\title{
Single port robotic surgery: my way or highway?
}

Urologic surgery as a field has always been obsessed with advancement. In fact, new development is imperative in our field, without it, we would still be performing maximally invasive open surgery for several indications which now can be accomplished with minimally invasive way. Robotic assisted surgery is one of the technological developments after endourology and ESWL which has impacted our field tremendously. Robotic surgery has revolutionized the field of Urology over the past 20 years. Today, the da Vinci ${ }^{\circledR}$ Robotic System (Intuitive Surgical; Sunnyvale, CA, USA) remains the most commonly used platform for robotic surgery, and is utilized by surgeons in multiple subspecialties. Intuitive Surgical has released five da Vinci ${ }^{\circledR}$ models including the standard, streamlined (S), S-high definition (HD), S integrated (Si)-HD, and $\mathrm{Xi}$ systems until last year. As the surgical systems continue to evolve with new technologies, SP (single port) robotic surgical system another edition in the field which was added last year in June 2018. Minimizing the number of port incisions during minimally invasive surgery, perhaps, one of the motives to use SP system in a certain subset of patients. At this time as it is a brand-new system and experienced surgeons are exploring its use to demonstrate safety and applicability. As a surgeon, we perform surgery to manage pathological condition. While there may be different surgical approaches to fix the problem, as a surgeon it behooves on us that we should be striving to fix the problem in the safest, effective and economical way that prevents the problem from coming back or getting worse. Every patient's history, anatomy, and physiology are vastly different besides biology of the disease. We should be utilizing these tools with utter care keeping in mind the balance of safety, efficacy, and cost. Of course, learning curve related to instrumentations and working on it can be learnt over a period of time. The biggest challenge is to prove whether it really improves patient outcomes while comparing with the standard robotic platform such as Xi. This begets the big question is this an improved surgical technique or is it just another way of performing surgery? For an oncologic indication patient wishes best oncologic, perioperative, postoperative outcomes and cosmetic outcome is a last priority having one large scar $v s$. multiple small scars. While the SP robotic surgical system have successfully reported feasibility of the technique, however, recently published reports perioperative variables remained insignificantly different, length of operating room time is longer. In reality, unless we don't have great data to suggest a SP approach is better than MP (multiport) approach it may not be a highway in the field of major uro-oncology surgeries. This focused Issue on "robotic-assisted urologic surgery" in Translational Andrology and Urology is a tour de force incorporating newer developments in the field of uro-oncology, reconstructive surgery, female urology and recent technological development such as single port surgery by the contributors who are truly pioneers and experts in the field of robotic surgery. I am personally grateful to all the individual contributors of this issue.

\section{Acknowledgments}

Funding: None.

\section{Footnote}

Provenance and Peer Review: This article was commissioned by the editorial office, Translational Andrology and Urology for the series "Robotic-assisted Urologic Surgery" without any funding or sponsorship. The article did not undergo external peer review.

Conflicts of Interest: The series "Robotic-assisted Urologic Surgery" was commissioned by the editorial office without any funding or sponsorship. AKH served as the unpaid Guest Editor of the series and serves as the unpaid editorial board member of Translational Andrology and Urology from May 2019 to Apr 2021.

Ethical Statement: The author is accountable for all aspects of the work in ensuring that questions related to the accuracy or integrity of any part of the work are appropriately investigated and resolved. 
Open Access Statement: This is an Open Access article distributed in accordance with the Creative Commons AttributionNonCommercial-NoDerivs 4.0 International License (CC BY-NC-ND 4.0), which permits the non-commercial replication and distribution of the article with the strict proviso that no changes or edits are made and the original work is properly cited (including links to both the formal publication through the relevant DOI and the license). See: https://creativecommons.org/ licenses/by-nc-nd/4.0/.

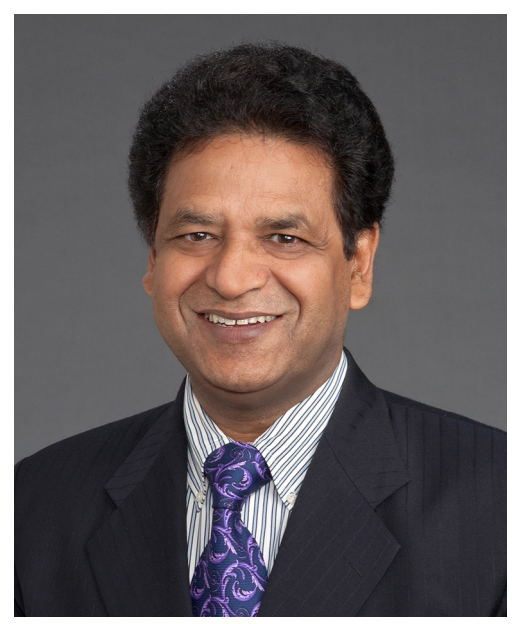

Ashok K. Hemal

Ashok K. Hemal, MD, MCh, FACS, FAMS, FRCS(G)

Professor, Department of Urology, Wake Forest Baptist Medical Center \& Wake Forest School of Medicine, Winston-Salem, NC, USA. (Email: ahemal@wakehealth.edu) Submitted Dec 17, 2019. Accepted for publication Dec 30, 2019. doi: $10.21037 /$ tau. 2019.12 .33

View this article at: $10.21037 / \operatorname{tau} .2019 .12 .33$

Cite this article as: Hemal AK. Single port robotic surgery: my way or highway? Transl Androl Urol 2020;9(2):846-847. doi: $10.21037 /$ tau.2019.12.33 